\title{
Cyclosporin treatment of a woman with acquired haemophilia due to factor VIII:C inhibitor
}

\author{
G. Pfliegler, Z. Boda, J. Hársfalvi, M. Flóra-Nagy, B. Sári, K., Pecze and K. Rak
}

Second Department of Medicine, University Medical School, H-4012 Debrecen, Hungary.

\begin{abstract}
Summary: A 47 year old woman is reported who had life-threatening bleeding due to the spontaneous development of factor VIII:C inhibitor. Cyclosporin combined with prednisone resulted in a full recovery and complete elimination of antibody even when other therapeutic facilities failed to be effective.
\end{abstract}

\section{Introduction}

Inhibitors against factor VIII:C (FVIII:C) develop not only in patients with congenital haemophilia $\mathrm{A}$ but also in non-haemophilic patients with autoimmune disorders, malignancies and in association with certain drugs or without any detectable underlying disease. ${ }^{1,2}$ Since, in these cases, clinical bleeding is a frequent and severe complication, the elimination of the inhibitor is desirable but is often difficult to achieve. ${ }^{3}$

We report a 47 year old woman with a severe haemorrhagic diathesis in whom cyclosporin and prednisone treatment completely eliminated antibody and allowed a full recovery.

\section{Case report}

The 47 year old woman had no family history of bleeding disorder. She had had three deliveries without any complications. In March 1986 she was admitted to hospital because of massive haematuria and widespread bruising. Acquired haemophilia with a high titre factor VIII:C inhibitor of 500 Bethesda units (BU) was diagnosed. Cryoprecipitate, non-activated prothrombin complex concentrate (PCC; $500 \mathrm{U} /$ day) and prednisone $(50 \mathrm{mg} /$ day) were given and plasma exchange (2.5-3 litres every other day) was performed. In 10 days only prednisone was continued, the bleeding stopped and she was discharged home with a small maintenance dose $(10 \mathrm{mg} /$ day $)$ of prednisone.

Three months later she developed a subarachnoid haemorrhage and 5 days later was transferred to our clinic. Laboratory findings on admission were: prothrombin time 13.3 seconds (normal range 12-14 seconds), activated partial thromboplastin time (APTT) 84.6 seconds (normal range 35-45 seconds),

Correspondence: Professor K. Rak, M.D.

Accepted: 1 December 1988 thrombin time 26.1 seconds (normal range 18-22 seconds), fibrinogen level $3.32 \mathrm{~g} / 1$ (normal rangej 2-4 g/l), platelet count $250 \times 10^{9} / 1$, template bleeding time 600 seconds (normal range 120-420 seconds) Platelet response to ADP, arachidonic acid, collagen。 adrenaline and ristomycin (an equivalent to ris ${ }^{-}$ tocetin ${ }^{4}$ ) was normal. APTT was repeated with $50 \%$ patient's plasma and $50 \%$ normal plasma aftes 2 hours' incubation 75.8 seconds, FVIII:C level $1.1 \%$ (normal above $60 \%$ ), plasma von Willebrand factoro antigen (vWFAg) $143 \%$ (normal range 70-140\%) vWF ristocetin/ristomycin cofactor assay $76 \%$ (n) mal range $70-140 \%$ ), Bethesda inhibitor assay FVIII:C positive at a level of 155 units $/ \mathrm{ml}$. Serump biochemistry was normal.

To stop bleeding and promote reduction of FVIII: antibody titre, non-activated prothrombin complex concentrate (PCC, 100,000 U in 12 days) in combinao tion with prednisone $(50 \mathrm{mg} / \mathrm{day})$ and cyclophos phamide (100 mg/day) were administered. (To avoid rise in FVIII:C antibody we refrained from the use of cryoprecipitate or factor VIII:C concentrates). APT shortened (on the 15th day of treatment: 67. $\vec{b}$ seconds), but on the 21 st day of hospitalization the APTT was again prolonged (121.0 seconds). Treati ment was completed with activated PCC (Feiba Immuno, $5000 \mathrm{U}$ for 2 days) but this combination alse failed to markedly shorten APTT (91.4 seconds). The neurological condition improved but haematuris developed.

In an attempt to reduce the inhibitor level and reduce the risk of another haemorrhage we administered cyclosporin A (Sandimmun, SandozN $4 \mathrm{mg} / \mathrm{kg} / \mathrm{day}$ ). All other therapeutic measures were stopped except prednisone $25 \mathrm{mg} /$ day. Though the APTT was slightly further prolonged the generaf condition of the patient somewhat improved. On the 5 th day of cyclosporin therapy, the serum bilirubin and transaminase levels rose. Investigation suggeste ${ }^{\circ}$

(C) The Fellowship of Postgraduate Medicine, 198 㝏 
a diagnosis of a non-A, non-B hepatitis. She was free from human immunodeficiency virus (HIV) infection. During the icteric period another 20,000 U of PCC were given and the prednisone was increased to $50 \mathrm{mg} /$ day. No bleeding occurred, APTT shortened (63.5 seconds). In 2 weeks transaminase and bilirubin levels returned to normal and cyclosporin $(4 \mathrm{mg} / \mathrm{kg} / \mathrm{day})$ was readministered.

On the 55th day she was discharged. As the APTT was still 69.8 seconds and antibody titre was $40 \mathrm{BU}$ cyclosporin was continued in combination with a small dose $(10 \mathrm{mg} /$ day $)$ prednisone. Three weeks later cyclosporin was reduced $(2 \mathrm{mg} / \mathrm{kg} /$ day $)$ and prednisone was given only every other day $(10 \mathrm{mg})$. During the clinical course no alteration in renal function could be detected. Cyclosporin was stopped in September 1987 (FVIII:C inhibitor activity 2.4 BU, APTT 49.1 seconds) and only prednisone continued. The following month she underwent an uneventful urgent cholecystectomy. She took prednisone $(5 \mathrm{mg}$ every other day) for an additional 4 months. Now, 22 months after subarachnoid bleeding she is free from any complaints or bleeding tendency, the APTT is 35-45 seconds with an inhibitor level less than 0.5 BU. Therapeutic efforts, clinical events, APTT and FVIII:C inhibitor levels are summarized in Figure 1.

\section{Discussion}

We report the case of a 47 year old woman with a spontaneous factor VIII:C antibody resulting in haematuria and subarachnoid bleeding. Since she had a very high titre of antibody ( $500 \mathrm{BU}$ at time of the first bleeding) she belonged to the brisk immunological responders (type 1 antibody) in keeping with the therapeutic difficulties encountered. ${ }^{3}$

During the first bleeding episode she responded well to substitution therapy after the antibody temporarily had been removed by plasmapheresis. However, antibody was further produced and when the second, subarachnoid bleeding occurred even PCC and activated PCC combined with prednisone and cyclophosphamide were ineffective. This was not entirely unexpected since in controlled trials PCC and/or activated PCC proved to be beneficial only in about half the cases. ${ }^{5,6}$ The effect of replacement therapy or removing antibodies by plasmapheresis, even when successful, can only be transient and a 'spontaneous' disappearance of inhibitor in brisk responders is hardly expected: ${ }^{3}$ the antibodies might persist as long as 20 years. $^{7}$

Since FVIII:C antibodies are derived from immunocytes, the use of immunosuppressive drugs

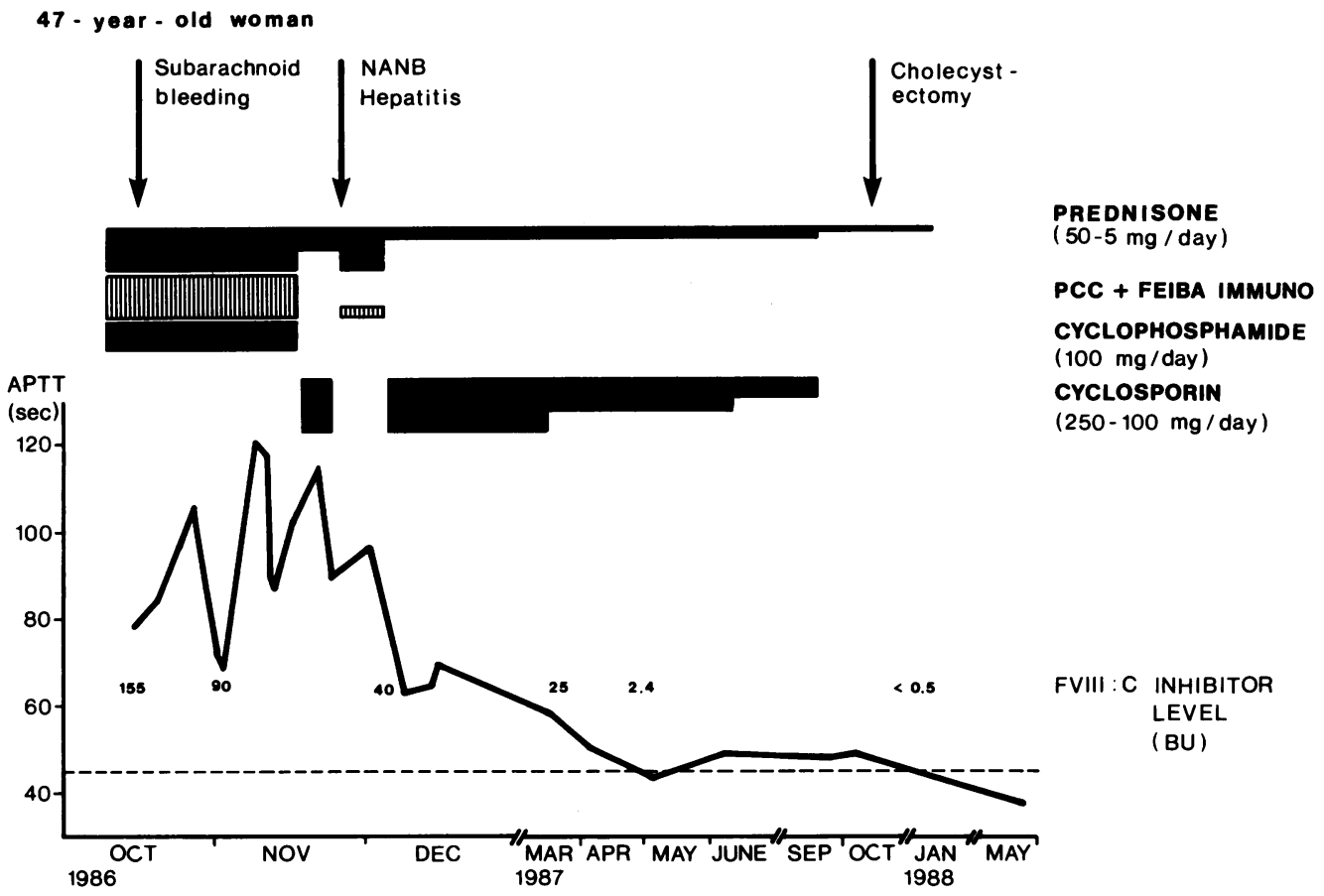

Figure 1 This figure shows clinical progress, activated partial thromboplastin time, FVIII:C inhibitor levels and therapy. 
seems to be reasonable. In the present case, however, the combination of prednisone and cyclophosphamide therapy failed to have any marked effect as in another recent case. ${ }^{8}$

Theoretically, an induction of immune tolerance against FVIII:C might be achieved either by disordering the regulation of immune response or by provoking a central unresponsiveness. ${ }^{9}$ Cyclosporin $\mathrm{A}$, by diminishing synthesis and release of interleukin-2, inhibits $\mathrm{T}$ helper cell function and also has a sparing effect on $T$ suppressor cell regulatory mechanisms. ${ }^{10,11}$ These effects promote a central unresponsiveness of the immune system. The excellent response of our patient to cyclosporin in combination with prednisone suggests that this treatment might be effective in non-haemophilic patients with high titre of antibody. In haemophilic patients, because of the high risk of HIV seroconversion, immunosuppression might be too hazardous (Bloom, A.L., personal communication). Similar results were obtained in a dog with severe haemophilia A and factor VIII:C antibody. ${ }^{12}$

\section{References}

1. Green, D. \& Lechner, K. A survey of 215 non-hemophilic patients with inhibitors to factor VIII. Thromb Haemost 1981, 45: 200-203.

2. Shapiro, S.S. Haemorrhagic disorders associated with circulating inhibitors. In: Ratnoff, O.D. and Forbes, C.D. (eds) Disorders of Hemostasis. Grune and Stratton, Orlando, Fl., 1984, pp. 271-284.

3. Bloom, A.L. Treatment of factor VIII inhibitors. In: Verstraete, M., Vermylen, J., Linen, H.R. and Arnout, J. (eds) Thrombosis and Haemostasis. University Press, Leuven, 1987, pp. 447-471.

4. Boda, Z., Solum, N.O., Sztaricskai, F. \& Rak, K. Study of platelet agglutination induced by the antibiotics of the vancomycin group: ristocetin, ristomycin, actinoidin and vancomycin. Thromb Haemost 1979, 42: 1164-1167.

5. Lusher, J.M., Shapiro, S.S., Palascak, J.E., Rao, A.V., Levine, P.H. \& Blatt, P.M. Efficacy of prothrombin complex concentrates in hemophiliacs with antibodies for factor VIII:C. A multicentre trial. N Engl J Med 1980, 303: $421-425$.

6. Hilgartner, M.W., Knatterud, G.G. and the FEIBA Study Group. The use of factor eight inhibitor bypassing activity (Feiba, Immuno) product for treatment of bleeding episodes in hemophiliacs with inhibitor. Blood 1983, 62: 36-40.

7. Coots, M.C. \& Glueck, H.I. An acquired inhibitor to factor VIII:C in a non-hemophiliac: twenty years of observation and characterization. Am J Hematol 1987, 24: 415-424.
Our observation is also in agreement with that of Hart et al. ${ }^{8}$ who found that in a 65 year old man witho acquired haemophilia resulting from a high titre of 3 FVIII:C antibodies, only cyclosporin and corti- $\varrho$ costeroid therapy proved to be effective.

A further observation in the present case was the $\overrightarrow{\vec{F}}$ gradual decrease of antibody titre (and shortening of APTT) in the course of hepatitis. From this point of? view it is worth noting that Ewing et al..$^{13}$ observed that $\frac{\bar{c}}{\bar{c}}$. HIV infection may make induction of immune $\overrightarrow{\widetilde{\sigma}}$ tolerance easier to achieve. A 'disordered regulation of $\varrho$ immune response' ${ }^{8}$ might explain these surprising $\tilde{\omega}$ findings.

The slight prolongation of bleeding time found in our patient, though not characteristic of factor VIII:C $\vec{\omega}$ deficiency, is not unexpected. In a patient with acquired VIII:C inhibitor Ganly et al. ${ }^{14}$ reported a $\frac{O}{Z}$ marked prolongation of bleeding time with normal:platelet count, function and normal amount of voner Willebrand factor. A possible explanation might be changes in multimer pattern of the molecule.

8. Hart, H.C., Kraaijenhagen, R.J., Kerchaert, J.A.M., Verdel, G., Freen, M. \& Van de Wiel, A. A patient with a spontaneous factor VIII:C autoantibody: successfal $\vec{c}$ treatment with cyclosporine. Transplant Proc 1988, (Suppl 3): 323-328.

9. Kazatchkine, M.D. Immunological basis for the indut tion of specific tolerance with special reference to factor VIII. In: Mariani, G., Russo, M.A., Mandelli, F. (eds) Activated Prothrombin Complex Concentrates. Praeger, 응 N.Y., 1982, pp. 185- 193.

10. Hess, A.D. \& Colombani, P.M. Mechanism of action: In: Borel, J.F. (ed.) Cyclosporini Progess in Allergy. Vol 38, 윽 Karger, Basil. 1986, pp. 198-221.

11. Van Buren, C. Cyclosporine: progress, problems, and perspectives. Surg Clin North Am 1986, 66: 435-449.

12. Pijnappels, M.I., Briet, E., van der Zwet, G., Huisden, R., van Tilburg, N.H. \& Euederink, F. Evaluation of the cutide bleeding time in canine haemophilia A. Thromb Haemost 1986, 55: 70-73.

13. Ewing, N.P., Sanders, N.L., Dietrich, S.L. \& Kasper, $\delta$ C.K. Induction of immune tolerance to factor VIII in 3 hemophiliacs with inhibitors. JAMA 1988, 259: 65-80.

14. Ganly, P.S., Isaacs, J.D., Laffan, M.A., Haslett, C. \& Hows, J.M. Acquired factor VIII inhibitor associated $\frac{D}{O}$ with lung abscess. Br Med J 1987, 295: 811. 